\title{
Towards sustainable development indicators
}

\author{
Hans Opschoor and Lucas Reijnders
}

\section{Introduction}

The economy and the natural environment interact. The condition of one is of importance to the other. On the one hand, economic activity is based on the continued availability of sufficient material and energy resources and an environment that is sufficiently clean and attractive. Insofar as the economy is based on renewable resources, the proper functioning of natural processes and systems may become an essential precondition for society's continuity. On the other hand, by discharging pollution and by other features associated with human activities, society is interfering with these environmental processes and systems. In this paper a first attempt is made to arrive at a system of indicators of the condition of the environment in terms of its capacity to sustain economic activity. Sustainability indicators reflect the reproducibility of the way a given society utilizes its environment. Hence, they differ from classical environmental indicators: they do not simply reflect environmental conditions or the pressures on the environment, but they indicate to what degree certain pressures or environmental impacts the earth can deal with in a long-term perspective, without being affected in its basic structures and processes. We refer to this capacity of the environment as 'ecological viability'. In a sense, therefore, sustainability indicators are normative indicators: they relate actual, 'objective' developments to a desirable condition or goal.

Loosely formulated, the objective of this exercise is to find measuring rods that can assist researchers and policy evaluators in answering questions such as: "is this country's or that region's performance more sustainable in 1991 than it was in 1981 ?". Hence we need to start from some presupposition of what these measuring rods ought to look like (Section 2), and we need to consider the implications of applying them to specific countries or regions (the imputation problem of Section 3). We will come face to face with the need to give substance to the notion of ecological viability (Section 4) and how this is to be defined when taking into account possibilities to replace natural assets by man-made ones (the substitution problem of Section 5). Sections 2 through 5 relate societal developments and environmental change to various notions of sustainability. We shall subsequently touch upon two 
more technical issues (the aggregation and indicator construction problems, Section 6) and finally present some examples of actual or possible sustainability indicators (Section 7).

\section{Environmental Indicators and Sustainability Indicators}

For the purposes of this Chapter environmental indicators can be defined as quantitative descriptors of changes in either (anthropogenic) environmental pressure or in the state of the environment. The former type of environmental indicators will be referred to below as 'pressure indicators' and the latter as 'environmental effect indicators'.

Environmental pressure indicators express (changes in) the amounts/levels of emissions, discharges, depositions, interventions, etc. in a predetermined region. The pressures exerted by society on the environment are commonly categorized as follows: a) pollution, b) overexploitation of resources, and c) landscape and ecosystem(s) and/or organisms modification. Pollution entails the introduction into the environment of substances or energy residuals that (may) have a negative impact. Overexploitation refers to ways and levels of 'cropping' or 'harvesting' natural resources, so that their future supply is at risk. Modification of ecosystems and landscapes can take the form of changes in physical structures in such a way or at such levels that the systems' integrity is in jeopardy by, for instance, too large a reduction in size of groundwater table changes. Even within small countries such as the Netherlands the number of different types of pressures on the various environmental compartments (air, water soil), resources, landscapes and ecosystems tends to become very large. Environmental pressures can be regarded as structural or incidental shocks that are transformed and transported in a variety of natural processes (biological, chemical, hydrological, atmospheric) manifesting themselves into changes in conditions in the environments of various receptors. These receptors include human beings, populations of plants and animals, resources, ecosystems, landscapes, and artefacts. The relevant environmental conditions can be regarded as so many dimensions of the concept of 'environmental quality': the potential(s) of the environment to satisfy demands by the various categories of receptors.

Environmental effect indicators express the consequences of environmental quality changes in terms of their effects on certain (predetermined) receptors, as enumerated above. For human beings, for instance, effect indicators could include repercussions on the pattern of welfare over time, and health indicators. For other species one could monitor environmental effects by looking at qualities and sizes of populations, niche size or biotopes. At the ecosystems' level, effect indicators could include integrity, biological diversity and buffering capacities. 
When attempting to develop sustainability indicators, one has to make choices as to the relevant types of environmental change. We opt for a broad approach, whereby a wide range of receptors as listed above is taken as the starting point. This implies an elaboration of the notion of sustainability beyond that of purely anthropocentric 'functionality' or utility (see Section 4). If, furthermore, one wishes to develop a manageable set of indicators in terms of their numbers, one has to address the issue of how to aggregate, or select from, the large number of actual environmental (pressure or effect) changes (see Section 6). Starting from our initial summing up of types of environmental pressure, we suggest that there are at least three areas for which sustainability indicators are required: (i) pollution, (ii) resources, (iii) biological diversity.

As was noticed in Section 1, sustainability indicators are not simple 'state indicators' but rather indicators of states vis-à-vis some reference situation; the latter could either be some past environmental state ${ }^{1}$, or a future one that is regarded as more desirable than the present. Sustainability indicators are thus more than mere state descriptors; they are normative measures of the 'distance(s)' between current states and the reference situation. We are not merely interested in the amounts of acid produced over a certain area or deposited in some region, but we wish to relate such indicators to, e.g., policy-determined emission maxima or critical loads. These reference conditions operate as 'Plimsoll-lines' (the metaphor is Herbert Daly's) and the sustainability indicators measure the distance between the actual water level and the Plimsoll-line. As such, information on these distances may help in answering questions such as: is there scope for further economic development in a region? what is the urgency of taking pressure alleviating measures? is society moving towards an unsustainable pattern of economic activity? It goes without saying that there will be no single Plimsoll-line in this case: it will be a set of standards and conditions, and unfortunately these various elements may in fact be interrelated, thus providing analysts with a rather diffuse description of the reference situation. One way of visualizing this multidimensionality is by using the 'AMOEBA' model (Chapter 7, this Volume), where a circle's circumference depicts the reference situation and each radius is a dimension of sustainability; actual situations are points on these rays that will normally not lie on the circumference.

\section{Environment and economy as open systems}

An economy may be defined as a set of productive and consumptive activities (and the actors involved therein) within certain territorial boundaries, but the environmental

I A good example of indicators using a past situation as a reference point is provided by ten Brink in his notion of 'AMOEBA' (Chapter 7, this Volume). 
pressure and hence the question of an economy's sustainability draws attention to environmental changes beyond these boundaries.

Environments are open systems linked by various processes of transportation, migration, etcetera. The environmental impacts of economic activities may thus be transferred through environmental processes from one place to another, even beyond national boundaries. Acid deposition in Sweden as a consequence of combustion in the UK is one example; a higher incidence of flooding in Bangla Desh due to deforestation on the Himalayan slopes is another. Effects such as holes in the ozone layer and the greenhouse effect are examples on a global scale of the often long paths of pollutants through space, and the distances between sources and points where effects manifest themselves. Harvesting activities by one economy on a shared resource will affect the quality of the resource for all that use it. This phenomenon of spatial interdependency has several consequences. Firstly, as the environmental consequences of an activity may extend to other countries, the full sustainability impact of that activity involves adding the environmental impacts in all affected countries. Secondly, as a country's environmental quality may be burdened by influxes of pollution from abroad, there may be a divergence between an economy's direct burden on the environment on the one hand, and the change in its own environmental capital on the other.

Disregarding recharge and regeneration, country A's environmental capital $E(A)$ is decreased by: (i) the influx $\mathrm{M}(\mathrm{B})$ of degradation from other countries $\mathrm{B}$, and (ii) A's own domestic environmental pressure $\mathrm{P}(\mathrm{A})$. A's total Environmental Pressure EP(A) (i.e. the total of all environmental impacts of all relevant economic activities) equals $\mathrm{P}(\mathrm{A})$ plus $\mathrm{X}(\mathrm{A})$, which represents all of A's impacts elsewhere. These variables are related as follows:

$$
\mathrm{dE}(\mathrm{A})=\mathrm{P}(\mathrm{A})+\mathrm{M}(\mathrm{B})=\mathrm{EP}(\mathrm{A})-\mathrm{X}(\mathrm{A})+\mathrm{M}(\mathrm{B})
$$

This leads to a first moment of choice. Monitoring the development of an economy's environmental capital E (i.e. the total of all resource stocks, including environmental quality, within the territory), and monitoring the development of a country's EP, are exercises leading to different outcomes. One has to choose between monitoring either one, or monitoring both. We opt for the latter: monitoring both.

Furthermore, economies are normally open systems with levels of production and consumption linked by international trade flows. In such cases, a part of the environmental burden of a certain product or a certain activity in country A may occur in country B. An example is the deforestation and soil exhaustion in Thailand, associated with the cultivation of the cassava which, in the form of tapioca, is exported as pig feed to Dutch intensive pig farmers (van Amstel et al. 1986). Similarly, by exporting certain products, country A may itself face only part of the 
environmental problems associated with that product, namely the production related ones; it will not suffer the use related ones in the country of destination, C (Venne et al. 1989). An example is provided by drins or other pesticides that used to be produced in Europe (with pollution consequences there) but were mainly used in third world countries (with ecosystems damage and waste related problems in the consuming part of the world).

This raises two further questions: (1) should these environmental consequences of forwardly or backwardly linked foreign activities be aggregated to obtain a measure of overall environmental pressure; and (2) if so, in country B or C where they occur, or in country A where the activity is located that ultimately gave rise to these effects? The first question arises when one considers the environmental impacts of a certain activity to be the total of the impact of that activity itself and the impacts of all backwardly and/or forwardly linked activities. In terms of a country's sustainability this is no problem if all activities take place within the boundaries of that country, but this may not be the case. For reasons of putting responsibility for environmental degradation where it intuitively belongs, one may in certain cases wish to add the impacts in countries $\mathrm{B}$ and/or $\mathrm{C}$ to those of $\mathrm{A}$. This might be the case where one country deliberately uses the environments of other countries as additional resources to its own, without the other country being in a position to dissociate from such trade relationships (Opschoor 1989b). Examples of such asymmetric relationships can be found in South to North trade in primary products. However, for practical reasons it appears better to abstain from attempting to allocate the cumulative environmental pressure (cumulated, that is, over the various stages in the product life cycle) to one single country where one specific stage occurs. Various attempts at empirically doing so (either by applying input-output techniques -even in single-country situations- or simply statistically analyzing trade flows in terms of countries of origin and the likely environmental consequences of the production stage in those countries) have remained relatively unsuccessful (James, Jansen and Opschoor 1978; Vos 1982, Venne et al. 1989). Ignoring the environmental consequences in country B implied in its exports to A of intermediate or final products might result in too favourable an assessment of the environmental pressure related to A's economic process, but on the other hand, these consequences are the result of economic activities in $\mathrm{B}$ and will therefore show up in that country's environmental account. And if reasonably symmetric relationships in terms of market power prevail, then the country suffering the environmental costs of a trade link may be assumed to have wilfully accepted it, as a price to be paid for the overall gain through trade.

Based on practical considerations it is recommended to incorporate international trade related transboundary redistributions of accumulated environmental pressure only if sufficient empirical data is available to incorporate these interrelationships. 


\section{Environmental Viability}

The requirement of environmental viability is an ambivalent one in at least two respects: a) one may give it substance from an anthropocentric or an ecocentric point of departure; and b) one may regard it either in a static or in a dynamic context.

To begin with the first ambivalence: recently a plea was made for ensuring 'sustainable development' (WCED 1987) defined as: a pattern of development that meets the needs of the present generation without jeopardizing the ability of future generations to meet their own needs. This definition is clearly anthropocentric. The notion of sustainable development, however, is again not unambiguous (cf. Opschoor 1987 and 1989a). One can stress several aspects, notably the socioeconomic one and the environmental one. Given a sufficiently long time horizon and certainty about all relevant interactions between the economy and the ecology, the two would coincide; but for all practical purposes, the two emphases reflect different policies. As time horizons become shorter and as one is prepared to take more risks as to the environmental repercussions (or their reversibility) of current activities, the two interpretations may diverge:

(i) In "sustained economic growth" the emphasis is on economic growth within some (often rather relaxed and imprudently defined) side conditions related to environmental quality and resource utilization. Put in formal terms this interpretation implies: positive growth rates of consumption per capita, either for all future periods ('strong SD', Pearce et al. 1988) or such that the net present value exceeds zero ('weak SD', ibid.);

(ii) Alternatively, the "environmental sustainability" or "viability" of development could be stressed. In this interpretation, the emphasis is on the preservation of prudently and more stringently defined environmental capital (natural resource base plus environmental quality) to be passed on 'intact' to future generations, as a development potential.

Here, the latter interpretation is followed (and expanded below). This implies the continued presence of healthy and productive resource regeneration systems and adequate inputs (qualitatively and quantitatively) to allow these systems to function from at least an anthropocentric perspective. In order to render the notion of sustainability more operational, one has to be explicit about the exact nature of environmental quality, $\mathrm{E}$ for short. $\mathrm{E}$ can be regarded as a set of individual resource stocks and environmental quality levels, and we can say that 'sustainability' means that the time derivative of each element of the vector $E$ must be positive or zero. Alternatively, we can seek some sort of aggregate A (or vector $\mathrm{R}$ with fewer elements than $\mathrm{E}$ ) in physical terms (e.g., aggregating energy resources by expressing them in oil equivalents or Joules) and require that $\mathrm{dA} / \mathrm{dt}$ (or $\mathrm{dR} / \mathrm{dt}$ ) be positive or zero. 
From the point of view developed so far, constraints on environmental exploitation can only be relevant if they follow from a logic based on an intertemporally extended societal self-interest. However, sustainability constraints may also result from other perspectives. For instance, ethical views may lead to restrictions on environmental exploitation based on the 'rights' to existence and development of nonhuman species and natural systems. These rights would then in fact curb human use rights. Effectively this might imply placing a value on the 'integrity' of natural elements and structures, and on the 'diversity' in terms of species and systems (so-called 'biological diversity'). Integrity or diversity can to some degree be regarded as functional from an economic, anthropocentric perspective (e.g., the potential direct economic value of species the qualities of which have not yet been investigated or discovered, for e.g., nutritional or medicinal purposes). Secondly, diversity and integrity can to a large extent be regarded as a precondition for sustainability, as has been argued above. But these two functionalist lines of argument might not be sufficient to protect all possible species and ecosystems. For example, it could well be argued that the sustainability of the biosphere (or, for that matter, of China) would not be at stake if the Panda bear were to become extinct. A case could be made (on noneconomic grounds) that integrity and diversity are of a significance beyond the domain of a functionalist approach; as noted earlier, we accept that case. That means that we prefer to define 'sustainability' broadly, i.e. from a position with due regard for the 'interests' of other species. This gives additional support for one proposal made earlier, namely that a set of indicators for (or 'reflectors' of) environmental quality change ought to include one or more indicators for biological diversity or ecosystem integrity, related to some reference situation.

The second point to deal with is the choice between a static and a dynamic interpretation, especially when attempting to establish operational definitions of biological diversity. From a geological and evolutionary point of view, one cannot really defend taking any past situation as a reference point. Rather, one could think in terms of a steady state for resource stocks or resource stock potentials, and for natural cycles and ecological ('life support') processes, providing an ever preserved base line situation from which evolutionary development can take place. There still are choices to be made then, especially as to the choice-specific species and systems for which conditions are to be ensured. Based on notions of prudence (or precaution) there is, moreover, a case for defining reference conditions safely beyond the minima as defined by the current state of knowledge. A further point to decide relates to spatial distribution. Species and ecosystems development does not necessarily have to be guaranteed at every point in space where they happen to be present today. Local extinction is not necessarily incompatible with sustainability (broadly defined). National or regional authorities will have to define to what degree it is desirable to maintain current levels of biological diversity. In the Dutch situation, for example, we would argue that a further reduction of ecological integrity is unacceptable, and hence, 
that a base line of environmental/ecological conditions is established such that this integrity is safely ensured.

\section{Substitution}

In a functionalist perspective it is conceivable that one natural resource replaces the other (e.g., sugar cane as a substitute for fossil energy). When resources can thus be replaced, the unsustained use of a particular resource may not pose a problem in terms of economic survival of the activities using that resource. Substitution possibilities may also exist between natural resources and nonnatural ones, such as produced capital, knowledge and know-how. Hence, technological development or innovation may lead to an expanded range of options for substitution of one resource for another, and hence may ease the problematic nature of the sustainability issue. This fact implies that it may in actual practice prove complex to give concrete substance to the notion of 'sustainability'. It may be more advantageous to sell and burn up a given fossil energy resource, and invest the revenues in the development of alternative natural resources or even of artificial ones, than to preserve the fossil resource.

Economists, in substantiating the notion of sustainability, often feel inclined to transform all natural resource into one aggregate economic value $\mathrm{V}$ (expressed in monetary terms) by using existing or calculated resource prices. This entails the ideas (i) that correct values for each resource exist or can be determined, and (ii) that depletion plays no role or can be neutralized by substitution of one natural resource for another. This would then lead to the condition for sustainable development that $\mathrm{dV} / \mathrm{dt}>0$. Some economists (e.g., Solow 1986) have gone to the extreme of requiring no more than the nonnegativity of some value aggregate of all forms of capital, natural or man-made. This would imply the possibility of substitution, without constraints, of produced capital or even knowledge for natural assets. This may be considered the economist's equivalent of a perpetuum mobile. Pearce et al. modify the latter approach: they add a set of (physical) constraints on the use over time of certain essential stocks ER (these constraints may imply a 'critical minimum stock' approach). At first sight, this is an attractive modification; however, environmental considerations might in fact turn ER into a set with a rather substantial number of elements, which makes it less convincing or effective. Moreover, the set of prices required to carry out the transformation into value is notoriously lacking due to market imperfections. In Section 4, we advocated an approach in which the elements of ER would be selected from a noneconomic perspective, which in many cases implies that reference to market prices becomes irrelevant.

Still, an operational definition of sustainability requires an answer to two related questions: a) over which span of time do we wish to ensure sustainability, and b) 
how does one deal with proposals that allow for the substitution of man-made assets for environmental resources? The two questions are related to the extent that future research and development may broaden the scope for such substitution considerably.

The first question may be answered by the requirement that a set of physical stocks and conditions is handed over that at least ensures economic and evolutionary development potentials at their current levels. This means maintaining (or enhancing) the quality of the present environmental infrastructure and biological diversity, or (at least) a steady state in terms of all essential environmental structures and processes. Examples are: putting no more fertilizer on agricultural land than is taken up by crops and livestock; depositing no more acid than present ecosystems can safely absorb or buffer; cropping trees at or below maximum sustainable yield.

The second question in our view leads to an approach of prudence or risk aversion when it comes to assessing the possibilities for substitution of one resource for another and for science's and technology's capacities to continuously render new substitution options. This can be incorporated into the Pearce approach. Stocks of resources will then only include proven stocks, and only proven new technologies using resources sustainably will be accepted as modifying the dependency of natural resources and hence the sustainability situation. For essential renewable resources this approach entails that: (i) the stock levels to be maintained must be high enough to safely ensure optimal sustainable offtake, and (ii) the quality of the regenerative systems instrumental in regrowth processes be maintained beyond safe minimum levels of environmental standards.

\section{Selecting and Building Indicators}

The notion of indicators is an old one. OECD began work on Social Indicators in 1970 (Fox 1987), which resulted in a list of 33 specific indicators grouped under eight headings (OECD 1982). One of these is: "Physical Environment". The indicators listed there that relate to the natural environment are: (i) Exposure to Air Pollutants, and (ii) Exposure to Noise. It is clear that this does not adequately cover the environment-economy interactions we are concerned with here. A new set of Indicators for Sustainability needs to be developed. In the remainder of this Section, the focus will be on indicators more directly related to environmental quality and stocks. We will comment briefly on the following points: (i) the areas for which indicators would be needed; (ii) the indicators' scope, (iii) formal features, and (iv) the process of developing indicators. 


\section{Indicator Areas}

Indicaturs would have to be derived from the specific characteristics of the economyenvironment system. Some have argued in favour of one single overall indicator of environmental capital but it is felt that at least 3 are needed:

* pollution;

* resources: renewable, nonrenewable (and semi-renewable); and

* biological diversity.

We base this on the following considerations.

In a functionalist perspective one can distinguish between several types of sources of environmental services:

(i) nonrenewable resources such as oil reserves, iron ore deposits; no substantial natural augmentation or renewal takes place;

(ii) renewable resources such as forest stands, fish populations, agricultural crops, where regeneration of the resource is a function of initial stock levels and the quality of the regenerative systems;

(iii) semi-renewable resources such as soil fertility, solar influx, rainfall and groundwater levels: natural processes provide -at a given moment in time and at a given point in space- a recurrent but limited -and often uncertainsupply, where this supply is not a function of initial (stock) levels but sometimes of other environmental factors.

Ideally, sustainability indicators reflect this variety in circumstances and resource types. In what follows we develop some resource indicators especially for renewable and nonrenewable resources.

The absorptive capacities of an ecosystem for pollution and disturbance fall under category (iii) of resources, but are normally analyzed separately from the perspective of environmental pressure and environmental effects. Below, we shall follow this practice and develop some pollution related sustainability indicators.

A third category of sustainability indicators we propose to use has no necessary relationship with economic functions of the environment vis-à-vis society, but has to do with the need to monitor ecological integrity or the 'naturalness' of landscapes and ecosystems by reflecting (changes in) biological diversity (i.e. both species diversity and ecosystems diversity). The rationale for including this aspect of environmental change has been given in earlier Sections.

\section{Indicator Scope}

The literature on indicators of sustainability has produced a wealth of dimensions that would have to be incorporated in them (e.g., Liverman et al. 1988), including 
(apart from 'sustainability') efficiency and equity. It can be argued that 'integrity' and 'manageability' are important dimensions as well. It is suggested here that future work will focus on the notions of sustainability, integrity and manageability. Thus, indicators would be required with a scope wide enough to reflect:

a) the factual developments in the use of environmental resources; here, one may be interested in establishing macro indicators of:

a.1) the overall environmental pressure EP, i.e. the environmental impacts of economic activities and environmental management (for instance, aggregates of pollution, resource inputs, spatial claims);

a.2) the change of environmental capital $\mathrm{E}$, or the 'state of the environment' (aggregate indicators for stocks of environmental assets, ambient environmental qualities, biological diversity).

b) the potentials for management towards sustainability; this would, for instance, require indicators for:

b.1) current or anticipated development in science and technology in terms of environmentally relevant products, processes, inputs;

b.2) the development of managerial tools, such as: appropriate institutions for environmental resource management, policy instruments, budgets, public support.

In what follows we shall concentrate on sustainability and integrity (biological diversity), and bypass the subject of indicators of manageability, important though it is. In other words, a.1 and a. 2 are elaborated here.

\section{Indicator Features}

In order to facilitate international comparison, indicators would have to be formated identically or analogously as much as possible. It is imperative to stress the need to severely limit the number of indicators, if they are to play a part in public decision making.

Liverman et al. (1988) have considered criteria that could be used in selecting indicators:

- sensitivity to change in time

- sensitivity to change across space

- sensitivity to change over social distribution

- sensitivity to reversibility

- sensitivity to controllability

- predictive ability

- integrative ability 
- relative ease of data collection

- relative ease of application.

It may not be possible to incorporate all these criteria adequately, or to do so while at the same time observing the recommendation that only a limited number of indicators is built.

\section{Indicators: Aggregates or Selections}

An important choice regarding formal features of indicators has to do with the nature of the indicators: are they to be true aggregates or transformations of underlying, more specific indicators, or are they to be selected ('typical' or 'representative' or 'critical') from larger sets? It is felt that the former is preferable but not always feasible, due to the vast amount of information necessary to duly reflect all relevant environmental processes and due to difficulties in formal aggregation.

Data reduction is a necessary step in indicator development. Sometimes one can relatively easily aggregate (e.g., when adding energy resources in terms of caloric value or oil equivalents, or in using acidification properties in combining $\mathrm{SO}_{2}, \mathrm{NO}_{\mathrm{x}}$ and $\mathrm{NH}_{3}$ emissions or depositions). Where such transformations using physical or chemical properties can no longer be made, economic weighing practices may be considered. Use could be made of market prices or stated preferences to add otherwise incomparable phenomena, but we have doubts as to the stability and acceptability of such procedures (see Chapter 4).

Sustainability indicators ideally provide insight into factual developments in the

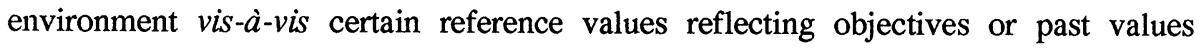
considered to be more desirable. This provides another possibility of aggregating the large number of individual indicators: determining the ratio of current environmental conditions and the corresponding reference values, and using mathematical techniques to aggregate these dimensionless figures in some way. Multicriteria analysis might be of great value here.

\section{Indicator Development}

The development of appropriate sets of such physical indicators is a laborious undertaking and is likely to involve many 'arbitrary' decisions (often based on pragmatic grounds such as data availability) on which variables to select and how to aggregate them (see previous paragraph). Logical steps in a process of deriving indicators would be: 
1. identification of the main natural elements of environmental capital and their interactions: ecosystems, life support systems, biogeochemical and hydraulic cycles, biological diversity, habitats, and the levels of integrity (completeness, 'naturalness') and purity (degree of pollution);

2. identification of the economically relevant features within these elements and their relationships to specific economic activities (either as inputs into, or receptors of outputs of, these activities);

3. selection of those elements that are quantitatively and/or qualitatively at risk, and a further analysis of these elements in terms of: a) their significance in regenerative and resource support systems, and b) substitution options for these resources in economic activities;

4. setting of standards/targets/critical levels with respect to the elements selected in 3., in relation to the notions of sustainability and minimum biological diversity to be maintained;

5. construction of indicators reflecting the development of environmental capital from the elements selected in 3., either by building aggregate variables or by picking specific items from that set of elements.

In step 5, one could opt for several possibilities:

a) express the selected items as rates or flows;

b) express them as rates-to-stocks;

c) if step 4 has been completed: express them as rates-to-goals or stocks-to-goals. Options b) and c) would enable further data reduction by turning the indicators into dimensionless figures. The procedure outlined here would preferably be fed into an information system linked with multicriteria methods, so that alternative choices in the various steps and alternative weights could be followed through in terms of their impact on the indicator values.

\section{Examples of Sustainability Indicators}

In this part of our paper we would like to present some examples of sustainability indicators. We will restrict ourselves essentially to indicators reflecting pressure on the environment. Examples of indicators relating to environmental effects will be given in the papers of Udo de Haes and ten Brink in this Volume. Our examples will mainly relate to deviations from a steady state.

However, we will also consider the case that an initial state cannot be considered acceptable in view of sustainability, in which case a steady state continuation of the initial state is not sustainable. 
Maintenance of a steady state is one of the operational definitions of sustainable development. A steady state is a dynamic state in which changes tend to cancel each other out. An example of a steady state is a constant atmospheric concentration of carbon dioxyde $\left(\mathrm{CO}_{2}\right)$. Such a constant concentration is the net result of a sizable emission and an equally sizable sequestration of $\mathrm{CO}_{2}$.

A steady state operationalization of sustainable development is appropriate (1) if the initial state is acceptable in view of sustainability; (2) if there is no time lag between changes in environmental parameters and effects (as occurs in the case of atmospheric $\mathrm{CO}_{2}$ ); (3) if sustainable development refers to many generations, and, (4) if at the end of the day there is no substitution of physical resources (like groundwater or ores) by nonphysical resources (like money or inventions).

Maintenance of a steady state in terms of resources, species and pollution would imply the following:

- use of (conditionally) renewable resources should - within a specified area and time span - not exceed the formation of new stocks. Thus, for instance, yearly extraction of groundwater should not exceed the yearly addition to groundwater reserves coming from rain and surface water.

- use of relatively rare nonrenewable resources, such as fossil carbon or rare metals, should be close to zero, unless future generations are compensated for current use by making available for future use an equivalent amount of renewable resources.

Thus, for instance, the use of rare metals like lead, indium or copper should be subject to virtually complete reuse. Dispersive use of lead in petrol would, for instance, violate this criterion.

Also, use of fossil carbon would be acceptable, provided that, for instance, an equivalent amount of biomass or other capturing devices for solar energy are put aside for use by future generations, and future generations are compensated for shifts in exploitation of fossil carbon following from exhaustion of convenient fossil carbon sources by this generation.

- Significant, though limited, use of relatively abundant nonrenewable resources such as iron or aluminum meets the steady state criterion, provided that there is compensation for an increase in exploitation efforts following from exhaustion of easily accessible and minable resources by this generation.

- Pollution that gives rise to accumulation of pollutants in one or more environmental compartments (e.g., atmosphere, sea, soil) in a first approximation violates a steady state operationalization of sustainability. The same holds for long-lasting pollution (for instance, groundwater pollution, radioactive pollution around Czernobyl), the safety of which is not established. Exposure to man-made mutagens affecting the germ line (involved in reproduction) should be close to zero. Violations of these first approximations 
to a steady state may be acceptable if future generations are fully compensated for associated damages.

- As to natural species in a first approximation the rate of extinction of species should not exceed the rate of origin. Additional steady state requirements may relate to diversity of ecosystems, integrity of ecosystems and the conditions for development of ecosystems.

A steady state operationalization of sustainability is rather strict. It is possible to use less stringent criteria for sustainability, for instance, depending on the perceived absence of unacceptable harm from pollution or extinction of species if it remains below specified levels.

Thus, for instance, Krause et al. (1989) have suggested a nonsteady state criterion for sustainable global warming. Whereas a steady state approach would require constant temperatures, they propose an upper level to global warming of $0.1^{\circ} \mathrm{C}$ per decade and an overall man-induced equilibrium warming of $2.5^{\circ} \mathrm{C}$, because such a warming would be compatible with adaptive possibilities of species and would remain within past natural fluctuations in the presence of homo sapiens.

\section{Indicators for conformity to or deviation from a steady state}

Indicators for sustainability should first and foremost indicate whether or to what extent a criterion for sustainability is met. The extent to which a criterion for sustainability is met may, however, also show temporal change, and more specifically a trend. Deviation from a steady state, for instance, may increase, decrease or remain roughly constant with time. Such a trend may also be reflected in an indicator. So, starting from a steady state operationalization of sustainability, one may define two indicators. First: a sustainability indicator indicating whether or to what extent the steady state criterion is met at a specified point in time or over a specified time span. Second: an indicator that reflects the temporal trend with respect to a steady state. Later we will introduce a third kind of indicator, which is appropriate in situations in which the initial state cannot be considered acceptable in view of sustainability. This we will call the sanitation indicator.

An indicator reflecting conformity to maintenance of a steady state is defined to be positive or zero when the steady state criterion is met. A positive value is given when there is improvement; for instance, when use of renewable resources is smaller than addition to stocks or when pollution levels decrease. An indicator reflecting a temporal trend with respect to a steady state is held to be zero or positive when the trend leads to conformity to a steady state either consistently or in due course. An indicator indicating conformity to a steady state will be negative when the steady state criterion is not met; for instance, because pollution levels increase. An indicator 
reflecting a temporal trend will be negative when developments do not lead to conformity to a steady state.

Indicators reflecting pressure on the environment may differ in spatial scope. For instance, the scope may be worldwide, continental, national or regional, or refer to a river basin. Values, including signs, of indicators may be different dependent on their geographical scope. Thus, for instance, although worldwide there is a loss of forests, violating the steady state criterion and thus presumably giving rise to a negative value for the sustainability indicator involved, particular countries may expand their forests, and this may be reflected in positive values for national sustainability indicators.

Applications of the steady state criterion may give rise to a large variety of environmental pressure indicators. Here we would like to give some examples of such indicators, and the signs these may have.

- The rate at which natural species die out is currently worldwide roughly $10^{6}$ times the rate of origin of species (May, 1988). Thus an indicator reflecting conformity to a steady state development should in this case be strongly negative. (It would be zero if extinction rates equalled rates of origin.) Estimates on the impact of business as usual up to the end of this century suggest that the rate of extinction (as a percentage of all remaining species) may remain roughly unchanged or even increase (Myers, 1979; May, 1988). Thus a sustainability indicator reflecting a temporal trend relative to a steady state development should also be strongly negative.

- The rate of increase in atmospheric concentrations of fully halogenated chlorofluorocarbons (CFC's) is estimated to have varied between 4 and $16 \%$ by the end of the 1980s (Prather and Watson, 1990; Reijnders and Kroeze, 1990). Because these CFC's currently cause significant and increasing deterioration of the ozone layer, an indicator reflecting current conformity to a steady state development will be negative. However, a 1990 London agreement on protection of the ozone layer aims at a phase-out of CFC production in industrialized countries by the year 2000 and in developing countries by 2010 . Although actual deterioration of the ozone layer is also dependent on other halogenated compounds, a phase-out of CFC production may contribute to stabilization of damage to the ozone layer and even to a final recovery of the ozonesphere. Thus a sustainability indicator reflecting the relevant temporal trend in conformity to a steady state development may be positive.

- Forested areas in the Netherlands are expanding. Currently there is a net increase in the amount of recoverable wood produced (addition to stock minus exploitation and die-back). Thus the indicator reflecting conformity to a steady state development may be considered positive. Long-term perspectives for 
forests in the Netherlands, however, are poor. Increasing acidification of soil threatens $\$ 9 \%$ of current forests with die-back (Nationaal Milieubeleidsplan, 1989), whereas a rise in atmospheric temperature may also negatively affect Dutch forests. Thus the relevant indicator reflecting the temporal trend is probably negative.

- Use of fossil carbon in industrialized countries is far from zero. Of total fossil carbon used probably less than $1-2 \%$ is recycled, whereas the remainder is transformed into wastes, including pollutants. There is some compensation for future generations through the planting of additional forest and the development of solar and wind energy, but overall there is no conformity to a steady state operationalization of sustainability. Thus the indicator reflecting compliance with sustainability of fossil carbon use should be negative. For the near future efforts have been announced by several countries to improve energy efficiency and increase recycling and the use of renewable sources of energy. Although this will not lead to compliance with a steady state use of carbon in the near future, the indicator reflecting the trend in compliance may be less negative than the indicator reflecting current conformity to a steady state development.

\section{Dimension and size of indicators reflecting conformity to a steady state}

If one sticks to an environmental capital approach to sustainability, it will not be possible to use the same dimension for all indicators. There is no sensible physical transformation that transforms, for instance, the dimension species (with which a steady state of living nature may be partially defined) into dimensions referring to use of fossil carbon or acidification of soil. However, there is the possibility of using the same dimension for groups of environmental variables. For instance, the use of nonrenewable resources may be related to presumable reserves, and may be measured with similar units (for instance, yearly use as a percentage of presumed total reserves). Similarly, greenhouse gases $\left(\mathrm{N}_{2} \mathrm{O}\right.$, tropospheric ozone, methane, carbon dioxyde and a number of halocarbons) may be lumped together on the basis of their global warming potential (for instance, in $\mathrm{W} / \mathrm{m}$ or ${ }^{\circ} \mathrm{C}$ ). Similarly $\mathrm{SO}_{\mathrm{x}}, \mathrm{NO}_{\mathrm{x}}$ and $\mathrm{NH}_{3}$ may be brought together on the basis of their acidifying effect on soil and surface water. Table 1 gives a number of examples of possible environmental pressure indicators, their aggregation levels, dimensions and sizes. 


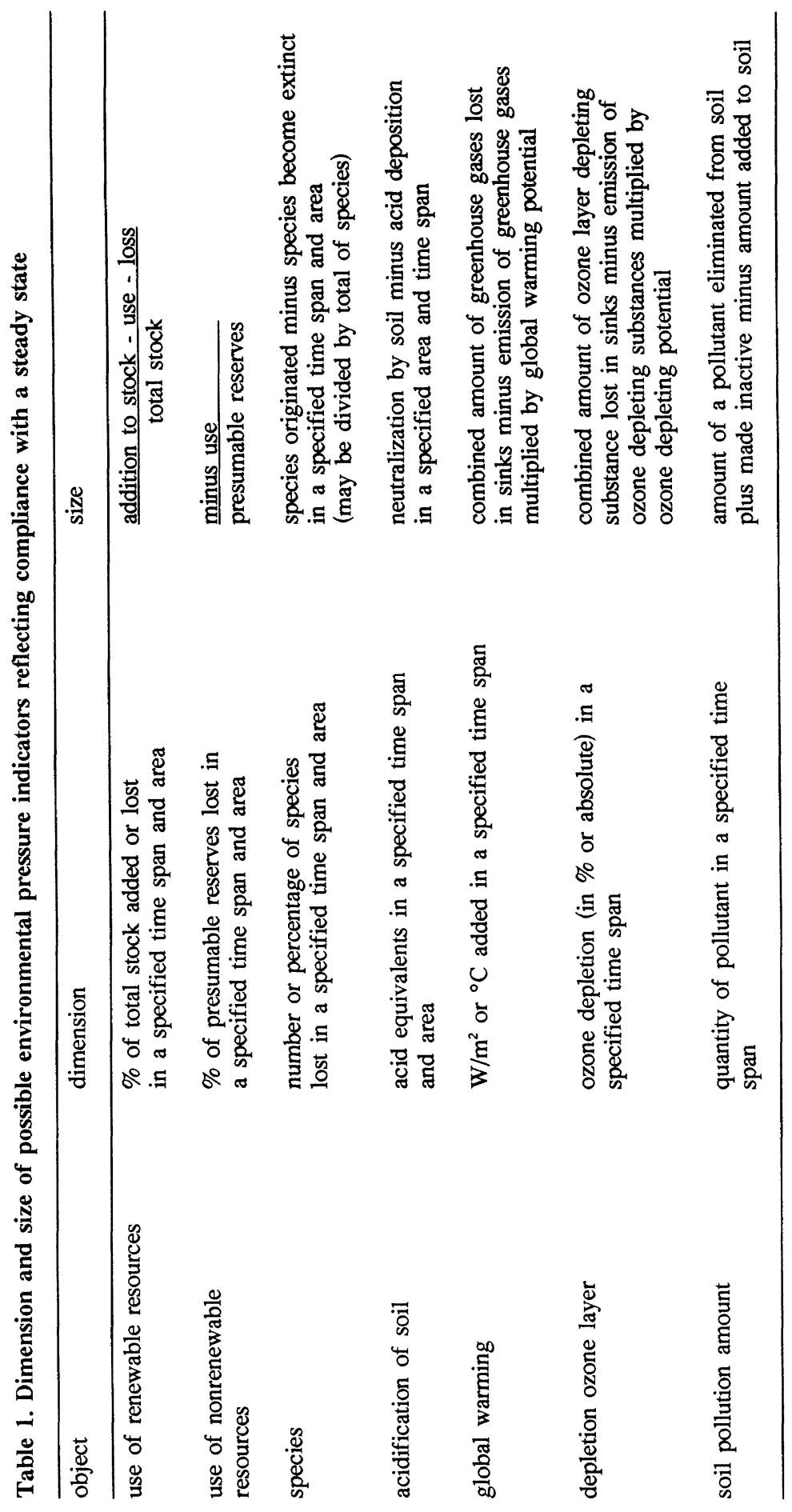




\section{$\underline{\text { Sanitation indicators }}$}

In a number of cases the situation (initial state) is such that a steady state with respect to this situation cannot be considered sustainable. Examples of current situations that are unacceptable from a sustainability point of view are chemical waste dumps and the hole in the ozone layer over the Antarctic. In such cases an indicator may reflect the extent to which sanitation is necessary before the situation may be considered sustainable. In the case of soil polluted by chemical waste a sanitation indicator may reflect the amount of polluted soil which is unfit for multifunctional use. Such a soil sanitation indicator will remain negative until a sanitation programme generating multifunctional soil from polluted soil is completed. Increasing the deviation from a sustainable state will increase the size of the sanitation indicator. So, for instance, further loss of ozone from the ozone hole over the Antarctic will make the relevant sanitation indicator more negative.

\section{Discussion and Recommendations}

The development over time of 'environmental capital' or even of 'environmental pressure' is not captured by traditional 'success indicators' such as GDP or National Income. Several proposals have been formulated to amend this by correcting GDP, but this approach threatens to be incomplete, or to lack transparency and credibility (see Chapter 4, this Volume).

A notion of 'sustainable income' could be defined and perhaps even quantified, only if so-called 'defensive expenditure', environmental stock depreciation, and the value of remaining environmental degradation could be assessed. Placing monetary values on them must be expected to continue to cause difficulties for the decades to come; some barriers are of an ethical nature. Given this situation, but also due to a need to explicitly know the quality of the environment, it is believed that there will always be a need for indicators expressing the development over time of environmental quality in physical terms.

Sets of environmental indicators should be developed at the level of resources or activities within a given country. In order to play a part in 'merging environment and economics in decision making' (WCED 1987) and policy development, the number of indicators proposed must be small. These indicators will have to cover the areas of: (i) resources (of all kinds: renewable, nonrenewable, semi-renewable ones), (ii) pollution, and (iii) the biological diversity or integrity of ecosystems.

Indicators are to reflect developments vis-à-vis net environmental pressure (EP) and/or environmental capital (E). Preferably, they are of the types of rates-to-stocks, or ratesto-goals. 
The scope of these indicators will have to be broad, ideally including observed sustainability and integrity impacts, but also the potentials for managing economic behaviour towards these objectives. The paper has not developed the notion of indicators for managing capacities, but focused on the dimensions of sustainability and integrity.

\section{References}

Amstel, A.R. van et al. (1986). Tapioca for the Dutch Livestock Industry. IES Report R-86/7, Free University Press Amsterdam.

Fox, K.A. (1987). 'Environmental Quality in a New System of Social Accounts". Archibugi, F. and P. Nijkamp (eds.): Economy and Ecology: Towards Sustainable Development. Dordrecht/London: Kluwer Ac. Publ. 189-203.

James, D.E., H.M.A. Jansen and J.B. Opschoor (1978). Economic Approaches to Environmental Problems. Amsterdam: Elsevier Scientific Publ.

Krause, E., W. Bach, J. Koomey (1989). Energy Policy in the Greenhouse. Er Cerrito. Liverman, D.M., M.E. Hanson, B.J. Brown and R.W. Meredith, Jr. (1988). Global Sustainability: toward measurement. Environmental Management Vol. 12, no. 2, pp. 133-143.

May, R.M. (1988). Science 241: 1441 - 1449.

Myers, N. (1979). The Sinking Ark. Pergamon Press, Oxford.

Nationaal Milieubeleidsplan (1989). Kiezen of verliezen. Staatsuitgeverij, Den Haag. OECD (1982). The OECD List of Social Indicators. Paris: OECD.

Opschoor, J.B. (1987). Sustainability and Change (in Dutch: inaugural address). Amsterdam: Free University Press.

Opschoor, J.B. (1989a). No Deluge After Us: Preconditions for Sustainable Use of the Environment (in Dutch). Kampen: Kok Agora.

Opschoor, J.B. (1989b)"North South Trade, Resource Degradation and Economic Security". Bull of Peace Proposals Vol 20 (2): 135-142.

Pearce, D.W., E.B. Barbier and A. Markandya (1988). Sustainable Development and Cost Benefit Analysis. London:IIED/UCL.

Prather, M.J., R.T. Watson (1990). Nature 344: 729 - 734.

Reijnders, L., C. Kroeze (1990). Prevention of climate change. Stichting Natuur en Milieu.

Solow, R.M. (1986). "On the Intergenerational Allocation of Natural Resources".Scand. J. Ecs. 88(1)141-149.

Venne, H.M (ed), E.E.M. Baars, J.F. Feenstra J. et al. (1989). Environment and International Trade. Publicatiereeks Milieubeheer 1989/1. Min. of Envir. Management, The Hague.

Vos, J.B. (1982). "Consumptieve Activiteiten, Milieuverontreiniging en Energieverbruik in Nederland". In: Aiking $H$. et al. (eds) (1982), Mozaiek van de Milieuproblematiek. Amsterdam: Free University Press. 
World Commission on Environment and Development (1987). Our Common Future. Oxford: Oxford University Press. 